\title{
Perception and Awareness of Physiotherapy in Junior College Students
}

\author{
Radha Pachpor1, Neeraj Athavale ${ }^{2}$, Rachana Dabadghav ${ }^{3}$, Ashok Shyam", \\ Parag Sancheti ${ }^{5}$ \\ ${ }^{1}$ Intern at Sancheti Institute College of Physiotherapy, Pune \\ ${ }^{2}$ Assistant Professor at Sancheti Institute College of Physiotherapy, Pune \\ ${ }^{3}$ Research Coordinator at Sancheti Institute College of Physiotherapy, Pune \\ ${ }^{4}$ Orthopedic Consultant at Sancheti Institute of Orthopedics and Rehabilitation, Pune \\ ${ }^{5}$ MS Orthopaedic Chairman, Chairman of Sancheti Institute of Orthopedics and Rehabilitation, Pune.
}

Corresponding Author: Neeraj Athavale

\begin{abstract}
Introduction: Physiotherapy is an emerging field in healthcare with innumerable benefits and its demand continues to increase. Often asked what physical therapy is and what does a physiotherapist do? It is very difficult to restrict its definition to a few words since the profession is holistic in approach. The junior college students are eligible to pursue Bachelor of Physiotherapy degree. It is important to have awareness regarding the profession that is related to their field of interest.

Method: The cross sectional study was undertaken with the help of Google form which was distributed to 280 junior college students with biology as elective subject. Data was collected and statistically analyzed.

Results: $97.1 \%$ know physiotherapy as a health care profession. 53.9\% think that they need a referral from a doctor to visit a physiotherapist. Most of them got the information about the field from their relatives and doctors. $73.6 \%$ will consider it as a profession.

Conclusion: This study concludes that there is high awareness among the students of junior college but the perception about the field is varied.
\end{abstract}

Key Words: perception, awareness, career option, junior college students

\section{INTRODUCTION}

Physical therapists are movement experts who improve quality of life through prescribed exercise, hands-on care, and patient education. Physical therapists diagnose and treat individuals of all ages, from newborns to people at the top of life. Many patients have injuries, disabilities, or other health conditions that require treatment. But PTs also look after those that simply want to become healthier and forestall future problems. Physical therapists examine all people and then develop a treatment attempt to improve their ability to maneuver, reduce or manage pain, restore function, and forestall disability. Physical therapists can have a profound effect on people's lives. They assist people achieve fitness goals, regain or maintain their independence, and lead active lives. ${ }^{[1]}$

Physiotherapists assess each patient and develop a personalised plan, using different treatment techniques so as to treat the underlying condition. Physiotherapists help in reducing pain, regaining range of motion, maintaining quality of life in patients plagued by chronic conditions, regaining strength after injuries and promoting health and ergonomics. The practice of physiotherapy shouldn't be defined by the employment of modalities and massage but rather the mixing of a 
patient's history, examination and analysis of movement dysfunction.

Physiotherapy is employed in big variety of disease conditions like musculoskeletal dysfunctions and problems e.g. adhesive capsulitis, CRPS, Low back pain, joint stiffness; neurological disorders like stroke, Parkinson's, Guillain-Barre syndrome cerebral palsy etc; cardiorespiratory conditions like cystic fibrosis, pneumonia, COPD; sports injuries like ACL injuries, ankle sprains, geriatric injuries, burns, intensive care units. ${ }^{[2]}$

Physiotherapy is certainly much more than fixing musculoskeletal sports injuries and giving massage although that's perhaps the foremost common perception of the profession. The main objective of physiotherapy is rehabilitation which is defined as "The restoration of an individual part or parts back to normal or near normal function after a disabling disease, injury, addiction or incarceration,"[3]

According to Jackson (2004), lack of or poor knowledge about a profession may result in misconceptions about the profession and inter-professional conflicts. Thus, good awareness of the role of physiotherapy in health care delivery may influence its use and people can pay visit to physiotherapists directly with no reference.

Physiotherapy as a profession has evolved over the years from the utilisation of massage as treatment by Hippocrates to use of complex physical therapies to specialised physiotherapy services in healthcare settings. Despite the popularity and advances gained worldwide in physiotherapy remains not getting the importance it should get.

And when planning one's future career, it is important to have information about different occupations and professions that are associated with his/her field of study. Even though a few people have an idea about their future career pathways in advance, many students are uncertain about it. For most people, these plans are usually made during their early and late adolescence. A majority of school children are also unaware about career opportunities open to them and most of them analyse their career prospects by looking at the social status of the occupation of their choice and the opportunities for career development. [5][6]

In Indian education system generally students pursue the Physiotherapy course after their higher secondary course. The higher secondary course has various branches of studies like science, computing, Commerce. The scholars from science background are eligible to pursue health courses like Medicine, Physiotherapy \& Nursing. It's indispensable for the junior college students to have appropriate knowledge about the above courses so as to pick out those courses as their career. In an exceedingly nutshell, college students from the science field are the future Physiotherapists of India. It's important to them to have appropriate awareness about physiotherapy as a health care service and have a positive perception about the profession as a career. ${ }^{[7]}$

\section{MATERIALS AND METHODS}

Study design- Observational study

Sampling technique- Convenient sampling

Study set up- Junior college in Maharashtra Sample size- 280

Inclusion criteria - Students between the age of 15-18 studying in junior college in science field.

\section{Exclusion criteria - Unwilling subjects Procedure -}

Will receive informed consent from subjects<smiles>[AlH]</smiles>

Questionnaire will be distributed in the form of Google forms

Any doubts about the questions will be solved on the same day

Complete questionnaire will be received on the same day

Interpretation 
Outcome measure -Self made Questionnaire, face validated

\section{Statistical Analysis- Descriptive analysis}

Results were analysed using descriptive analysis frequency was calculated and percentage was found out for different tables and graphs.

\section{RESULT}

1. Do you consider physiotherapy as a healthcare profession?

\begin{tabular}{|l|l|}
\hline Yes & $97.1 \%$ \\
\hline No & $2.6 \%$ \\
\hline
\end{tabular}

2. From where are you taken physiotherapy from?

\begin{tabular}{|l|l|}
\hline Govt hospital & $2.6 \%$ \\
\hline Private clinic & $16.2 \%$ \\
\hline Not taken & $81.2 \%$ \\
\hline
\end{tabular}

3. From where did you get the information about physiotherapy?

\begin{tabular}{|l|l|}
\hline Relatives & $27.9 \%$ \\
\hline Doctors & $32.1 \%$ \\
\hline Friends & $14.3 \%$ \\
\hline Others & $25.7 \%$ \\
\hline
\end{tabular}

4. Have you ever taken physiotherapy treatment?

\begin{tabular}{|l|l|}
\hline Yes & $87.1 \%$ \\
\hline No & $12.9 \%$ \\
\hline
\end{tabular}

\section{If you ever had back pain whom would} you go to first?

\begin{tabular}{|l|l|}
\hline General Physician & $22.5 \%$ \\
\hline Orthopedic surgeon & $10 \%$ \\
\hline Physiotherapist & $24.6 \%$ \\
\hline Self-treatment taken & $42.9 \%$ \\
\hline
\end{tabular}

6. What treatment options are you aware of?

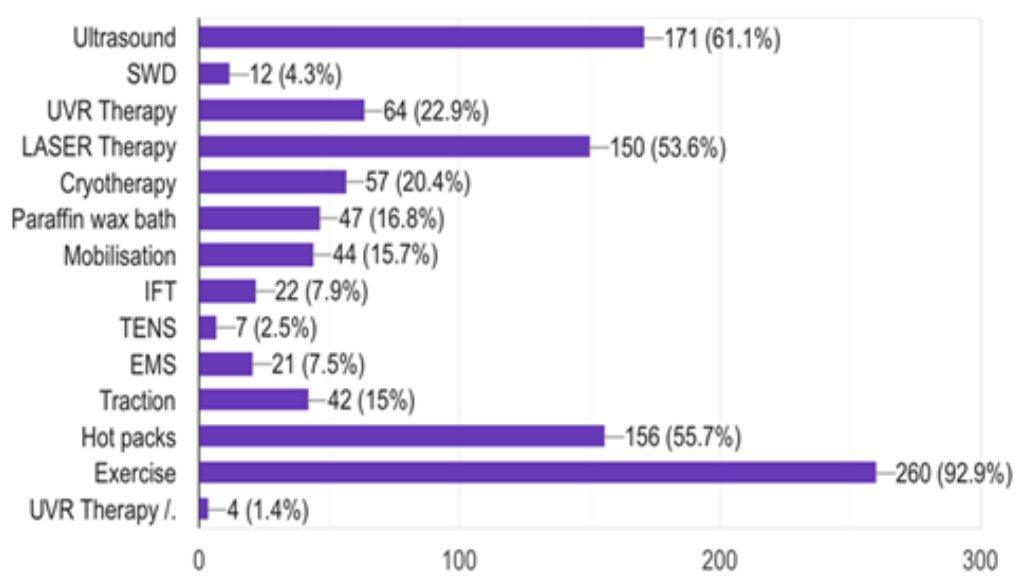

Graph 1

\section{Uses of physiotherapy}

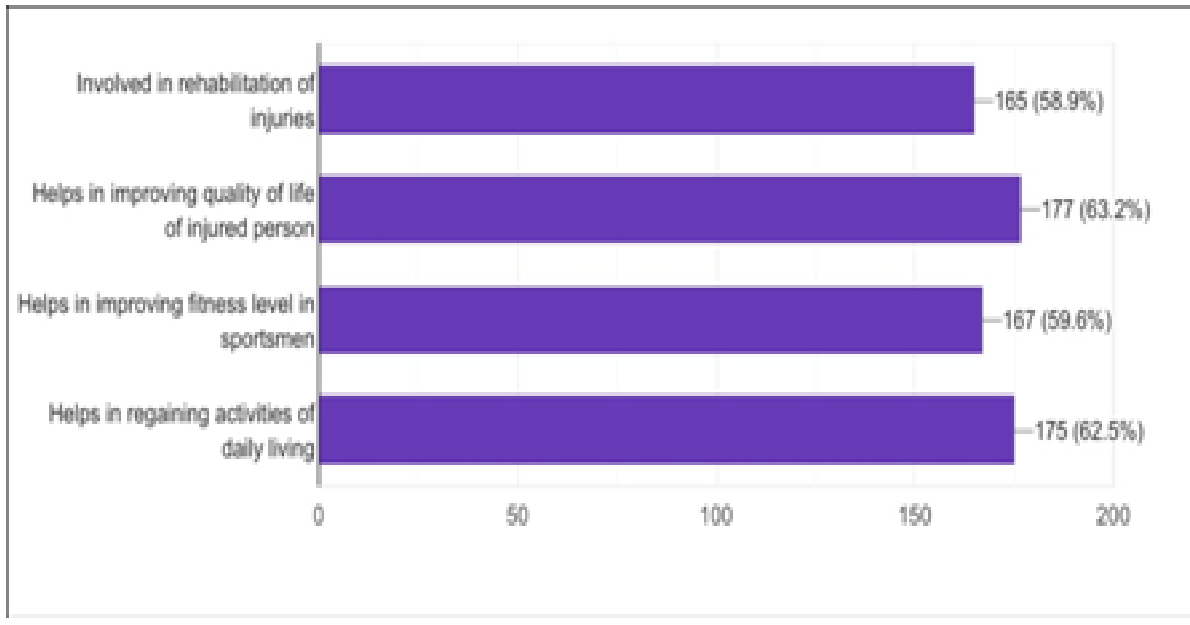

Graph 2 


\section{Role of physiotherapy}

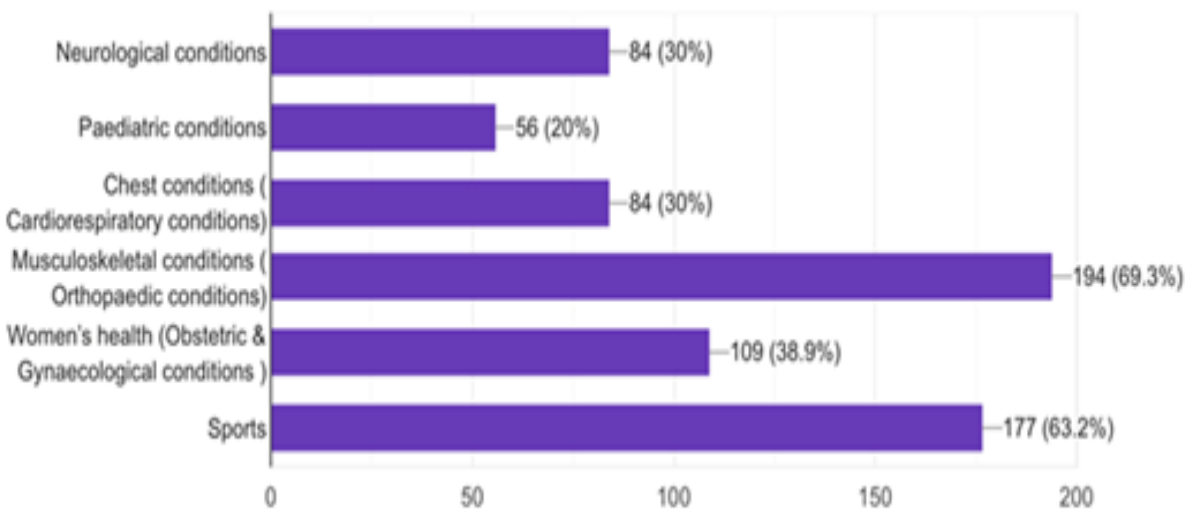

Graph 3

9. Would you consider physiotherapy as a profession?

\begin{tabular}{|l|l|}
\hline Yes & $73.6 \%$ \\
\hline No & $26.4 \%$ \\
\hline
\end{tabular}

10. What qualification do you think is needed to become a physiotherapist?

\begin{tabular}{|l|l|}
\hline Degree & $63.9 \%$ \\
\hline Diploma & $18.6 \%$ \\
\hline Certificate & $17.5 \%$ \\
\hline
\end{tabular}

11. Do you think you need a referral from a doctor to see a physiotherapist?

\begin{tabular}{|l|l|}
\hline Yes & $53.9 \%$ \\
\hline No & $46.1 \%$ \\
\hline
\end{tabular}

12. Do you think physiotherapists can have their own clinic or they always have to be affiliated with a hospital?

\begin{tabular}{|l|l|}
\hline Yes & $82.1 \%$ \\
\hline No & $17.9 \%$ \\
\hline
\end{tabular}

13. What is the duration of the physiotherapy undergraduate course?

\begin{tabular}{|l|l|}
\hline 2.5 years & $10.7 \%$ \\
\hline 3 years & $31.6 \%$ \\
\hline 4 years & $39.3 \%$ \\
\hline 4.5 years & $13.9 \%$ \\
\hline
\end{tabular}

\section{DISCUSSION}

This study was conducted to evaluate the level of awareness and perception of physiotherapy among junior college students. The preferred population is higher secondary science background students because they are the potential candidates to pursue bachelor of Physiotherapy course in India.
Often asked what is a physical therapy and what a physiotherapist does, it is very difficult to restrict its definition to a few words since the profession is holistic in approach. World Confederation of Physical Therapy (WCPT) defines Physical Therapy as "A health care profession which deals with human function and movement and helps patients in maximizing physical potential. It helps patient in improvising his quality of life by use of physical approaches in promotion, prevention, treatment / intervention and rehabilitation. ${ }^{[16]}$

A pilot study done by Harikrishnan, Kamalambal $\mathrm{H}$ et al., in 2016showed that the basic awareness about Physiotherapy among higher secondary students is not satisfactory. Many of them believe physiotherapy is practiced by doctors, it indirectly depicts majority of the students are not aware that physiotherapy is a unique profession and practiced by Physiotherapist.

Contradicting it, this study showed that $97.1 \%$ of students knew physiotherapy is a healthcare profession. Most of them got the information about this field from their doctors and relatives.

When asked about the uses of physiotherapy in various fields most of them were aware about physiotherapy's use in musculoskeletal conditions (69.9\%) and in sports $(63.2 \%)$. The similar findings were noticed in the study conducted by Riju 
among high school students in Anand district (India) ${ }^{[10]}$. Kacie who conducted a study among public at Kansas city, United states the highest awareness of Physiotherapy is musculoskeletal conditions (90\%).This study implicates the awareness about the role of Physiotherapy in other specialty (neurology, Cardiorespiratory, Women's health, Paediatrics) condition has to improved. Not even a single respondent is aware that Physiotherapy is useful in all the above awareness. Awareness about neurological conditions (30\%), paediatric conditions (20\%), cardiorespiratory conditions $(30 \%), \quad$ obstetric and gynaecological conditions (38\%) was found to be very poor. ${ }^{[11]}$ Similar findings were found in study conducted by Harikrishan. $\mathrm{R}$ most of the students were about role of physiotherapy in musculoskeletal conditions $(80 \%)$ and very less were aware about its use in paediatrics $(17 \%) .{ }^{[7]}$

Although the pandemic most of the students have become aware about the role of a physiotherapist in the society. However $87.1 \%$ of them have never taken physiotherapy treatment. Most of them preferred going to an orthopaedic surgeon or took self treatment instead of going to a physiotherapist. Maximum students are aware about the different treatment techniques like mobilizations, exercises, cryotherapy but are less aware about the electrical modalities like TENS,UVR therapy, EMS, SWD, paraffin wax bath. This finding is supported by the pilot study done by Harikrishna and Kamalambal ${ }^{[7]}$. According to that study most of the students were unaware about the different treatment modalities.

A study done by Pallavi Bargaje and Nilima Bedekar et al. in 2017 on Perception of junior college students about Physiotherapy as a profession showed that $40 \%$ of the students did not know that physiotherapists can practice independently hence supporting my other findings which showed that $53.9 \%$ students did not know that a reference from doctor is not needed to see a physiotherapist and they do not always have to be affiliated with a hospital. ${ }^{[14]}$

According to Ginzberg (1972) theory, between early to late adolescence is the period in which career choices are made. According to Super's developmental theory, individuals between the ages 15 and 24 years are at the scrutiny stage of their development. This phase is characterised by the making of logical choices and development of skills. ${ }^{[15]}$ In India the students will be in higher secondary level at the age of $15-18$ and that is the period to select their future career. Hence we have to provide adequate information about the profession so that the student may take Physiotherapy as a choice of career. ${ }^{[7]}$

\section{CONCLUSION}

This study concludes that there is high awareness among the students of junior college but the perception about the field is varied.

\section{ACKNOWLEDGEMENT}

I hereby take this opportunity to thank Sancheti College of Physiotherapy for giving me this golden opportunity to conduct a research which was well guided by the experts here. I would like to thank Dr. Neeraj Athavale (PT) for his constant guidance and motivation which helped to achieve the goal of completing this research project. I also would like to thank Dr. Rachana Nikam(PT), Dr. Ashok Shyam, Dr. Parag Sancheti and our principal Dr. Apurv Shimpi for their kind inputs and efforts which created interest amongst us regarding research. I would also like to thank the members of the Institutional Review board committee and the management to carry out my research.

Lastly I would like to extend my gratitude towards my batchmates and seniors for helping me carry out my research project as a whole. Lastly I would like to thank my family and friends for their constant motivation and support.

\section{Conflict of Interest: None}




\section{Source of Funding: None}

\section{Ethical Approval: Approved}

\section{REFERENCES}

1. What Physical Therapists Do. American physical therapy association.[10 June 10, 2021]Available at: https://www.apta.org/your-career/careers-inphysical-therapy/becoming-a-pt

2. Sheppard L. Changing the public perception of physiotherapeutic treatment. Health marketing quarterly. 1995 Feb 22;12(2):7796.

3. Mosby's Medical Nursing and Allied Health Dictionary. (2006), 7th edition, Mosby: St Louis.

4. Abichandani D, Radia V. Awareness of various aspects of physiotherapy among medical residents. J Int Med Res. 2015;4(10):1460-5.

5. Ogiwara S, Nozoe M. Knowledge of physiotherapy: a study of Ishikawa High School students. Journal of Physical Therapy Science.2005; 17: 9-16.

6. Gotlib J, Bialoszewski D, Sierdinski J, Jarosz MJ, Majcher P, Borczyk K, Bauer A, Anna C, Grzegorczyk J, Piaszewski M, Kulak W, Czupryna O, Prokopowicz K. A comparison of the perception and aspirations of third year physiotherapy students trained in three educational settings in Poland. Physiotherapy 2010; 96(1): 3032.

7. Harikrishnan R, Kamalambal H. Awareness and Attitude towards physiotherapy among higher secondary students: A pilot survey study. Int J Physiother Res. 2017;5(1):184651.

8. Agarwal Yashaswi, Agarwal Manish, Gupta Nalina. Awareness of Physiotherapy among Higher Secondary Students and Perseverance among Physiotherapy Students and Professionals in Meerut - A survey, Indian Journal of Physiotherapy \& Occupational Therapy 2012;6(1):176.

9. Thusharika D. Dissanayaka, Shayama Banneheka. Awareness in Physiotherapy among High School Students. International Journal of Scientific and Research Publications 2014;4(7):4.

10. RijuD.Patel. Awareness about Physiotherapy Among High School Students of Anand District. International Journal for Innovative Research in Multidisciplinary field 2015;1(1):4.

11. Kacie Rognlie, Yvonne Searls (2011).Public perception of Physical therapist scope of practice. Journal of student Physical Therapy Research 2011;4(2):10-17

12. Zakaria, Abd.Razak, HazleenaBaharun and ZuwatiHasim (2014). Prospect of Physiotherapy Profession and requirements for changes in High School Curriculum. 2014;1(2):65-70.

13. Osakinle E.O. In-School Adolescents and Career Choice: The Case OfEkiti State, Nigeria. Journal of College Teaching \& Learning. 2010;7(9):43

14. Bargaje PV, Bedekar NS, Rairikar S, Shyam A, Sancheti P. Perception of junior college students about Physiotherapy as a profession. Physiotherapy-The Journal of Indian Association of Physiotherapists. 2017 Jan 1;11(1):30.

15. Roopchand Martin S and Noel G. Secondary School students Knowledge of Physical Therapy. West Indian Med J. 2014;63(2):151-158.

16. Dash SS. Awareness of physiotherapy \& its scope among women in a community-a survey. Int J Physiotherapy Res. 2019;7(6): $3331-5$.

How to cite this article: Pachpor R, Athavale N, Dabadghav R et.al. Perception and awareness of physiotherapy in junior college students. Int $J$ Health Sci Res. 2021; 11(7): 243-248. DOI: https://doi.org/10.52403/ijhsr.20210733 